\title{
CORRESPON DENCE.
}

\section{ON THE PURCHASE OF A COMPLETE ANNUITY-INVESTI- GATION OF FORMULAS.}

To the Editor of the Journal of the Institute of Actuaries.

Sir, - I have had occasion to investigate some formulas for calculations connected with the purchase (as an investment) of a complete annuity, and as they differ, I believe, from the other formulas that have been suggested for use in similar cases, I venture to send you a note of them, that you may insert it in the Journal if you consider the matter of sufficient interest.

In purchasing a complete annuity as an investment, the annual income is held to consist of two parts, (1) the interest on the capital advanced, and (2) the premium for assuring its return. It is also assumed that the apportionment receivable at the death of the annuitant will amount on the average to six months' premium and six months' interest. Now as the premium ceases with the payment at the beginning of the year of death, while interest continues to aocrue till payment of the sum assured at, say, the $\frac{1}{m}$ th part of a year after death, the assurance in connection with an outlay of 1 should be $1-\frac{\pi}{2}+\frac{i}{m}$,--where $\pi$ is the premium actually payable at the rate $\mathrm{P}$ per 1. The value of $\pi$ is formed from the equation

$$
\pi=\mathrm{P}\left(1-\frac{\pi}{2}+\frac{i}{m}\right), \text { which gives } \pi=\frac{\mathrm{P}\left(1+\frac{i}{m}\right)}{1+\frac{\mathrm{P}}{2}} .
$$

Again, out of an outlay of 1 the vendor receives ouly $1-\pi$, since the first year's premium has to be deducted from the amount; and for this he requires to grant an annuity of $\pi+i$. It follows, therefore, since

$$
\pi+i: 1-\pi:: 1: \frac{1-\pi}{\pi+i}
$$


that the present value of an annuity of 1 is $\frac{1-\pi}{\pi+i}$, where $\pi=\frac{\mathrm{P}\left(1+\frac{i}{m}\right)}{1+\frac{\mathbf{P}}{2}}$ as above.

We have still to find the annual premium and the policy required in connection with the transaction. Calling the former $\pi^{\prime}$ and putting $a$ for the present value of the annuity $\left(\frac{1-\pi}{\pi+i}\right)$, we get the equation $\pi^{\prime}=\pi\left(\stackrel{a}{a}+\pi^{\prime}\right)$; whence the annual premium $\pi^{\prime}=\frac{\pi i}{1-\pi}$. Lastly, the sum to be assured $=\frac{\pi^{\prime}}{\mathrm{P}}$, that is $=\frac{\pi}{\mathrm{P}} \cdot \frac{a}{1-\pi}$.

It will be obvious that the expressions now given for the price, the premium and the policy may be stated in terms of $P$. But the resulting formulas are not nearly so practically convenient as those under the present arrangement, where the numerical value of $\pi$ is ascertained at first, and used throughout all the succeeding calculations.

I may explain, in closing, that my reason for undertaking the investigation was, that I wished to make allowance for the sum assured being payable four months after death; on the assumption that the time between proof of death and payment of the claim was three months, and that one month would be required for proof. In laying the results before your readers, however, I have exhibited the expressions in the more general form.

I am, Sir,

Your most obedient servant,

Edinburgh, December 1877. JAMES SORLEY. 